\title{
KIMURA DISEASE- A CASE REPORT ON UNCOMMON CAUSE OF CERVICAL LYMPHADENOPATHY
}

\author{
Bushra Nishat ${ }^{1}$, Mohd. Abdul Rehman'2, G. Santhi Vardhani
}

${ }_{1}^{1}$ General Surgery Resident, Department of General Surgery, Osmania Medical College and Osmania General Hospital, Hyderabad, Telangana, India.

${ }^{2}$ Assistant Professor, Department of General Surgery, Osmania Medical College and Osmania General Hospital, Hyderabad, Telangana, India.

${ }^{3}$ Associate Professor, Department of General Surgery, Osmania Medical College and Osmania General Hospital, Hyderabad, Telangana, India.

HOW TO CITE THIS ARTICLE:Nishat B, Rehman MA, Vardhani GS.Kimura disease- a case report on uncommon cause of cervical lymphadenopathy.J. Evolution Med. Dent. Sci. 2018;7(43):4700-4702, DOI: 10.14260/jemds/2018/1049

\section{PRESENTATION OF CASE}

A 17-year-old boy presented with the complaints of insidious onset of bilateral postauricular painless swelling since 1 year, which gradually increased in size and was associated with bluish discolouration of the skin above the swelling and not associated with fever, pain, itching, night sweats or ear discharge or weight loss. No history of chronic cough suggestive of pulmonary tuberculosis. No history of similar complaints elsewhere in the body. No family history of similar complaints.

On general examination, he was haemodynamically stable with no evidence of pallor or icterus or pedal oedema. On local examination, the swelling behind left ear was rubbery in consistency, non-tender, mobile, ovoid shape of size $3 \times 2 \mathrm{cms}$ with smooth surface and well-defined margins. Skin over the swelling showed bluish discolouration. The swelling behind the right ear was rubbery in consistency, non-tender with smooth surface and well-defined margins, round in shape $2 \times 2$ $\mathrm{cm}$ with normal skin over it. No axillary/ inguinal lymphadenopathy. No hepatosplenomegaly. Other systemic examination was unremarkable.

\section{CLINICAL DIAGNOSIS}

Chronic bilateral cervical lymphadenopathy of probable immune aetiology, with no local signs of inflammation and constitutional symptoms.

\section{DIFFERENTIAL DIAGNOSIS}

Angioimmunoblastic T-cell lymphoma, Langerhans cell histiocytosis, florid follicular hyperplasia, Castleman's disease, dermatopathic lymphadenopathy, ALHE, lymphadenopathy of drug reactions and parasitic lymphadenitis. Also, other entities such as Tuberculous adenitis, lipoma, Kikuchi's disease, Mikulicz' disease, Eosinophilic granuloma, ALHE (Angiolymphoid Hyperplasia with Eosinophilia),

'Financial or Other Competing Interest': None.

Submission 12-09-2018, Peer Review 06-10-2018,

Acceptance 12-10-2018, Published 22-10-2018.

Corresponding Author:

Bushra Nishat,

H. No. 12-2-422/61/A,

Priya Colony, Guddimalkapur,

Hyderabad-500028,

Telangana, India.

E-mail:bushnt@gmail.com

DOI: $10.14260 /$ jemds $/ 2018 / 1049$

(c) $(1) \ominus$
Cylindroma, Pyogenic granuloma;importantly Hodgkin's disease, Acute non-lymphocytic leukaemia andFollicular lymphoma. Except for Angiolymphoid hyperplasia with Eosinophilia, the clinical and histological features of these diseases easily distinguish them from Kimura's disease.(10)

\section{i) Preoperative Pictures}

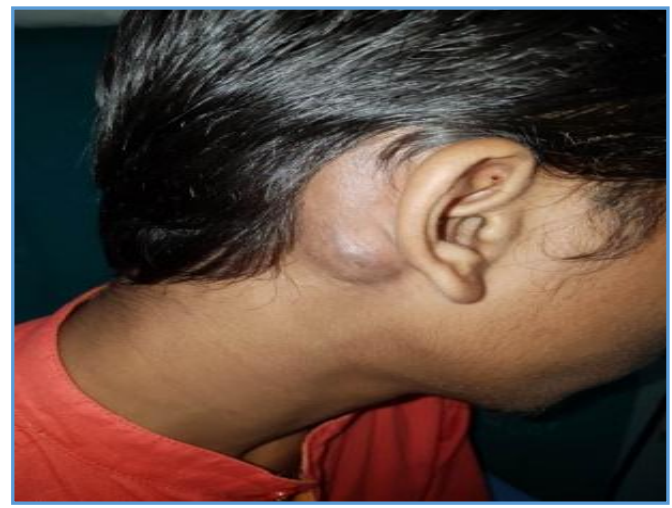

A. Right

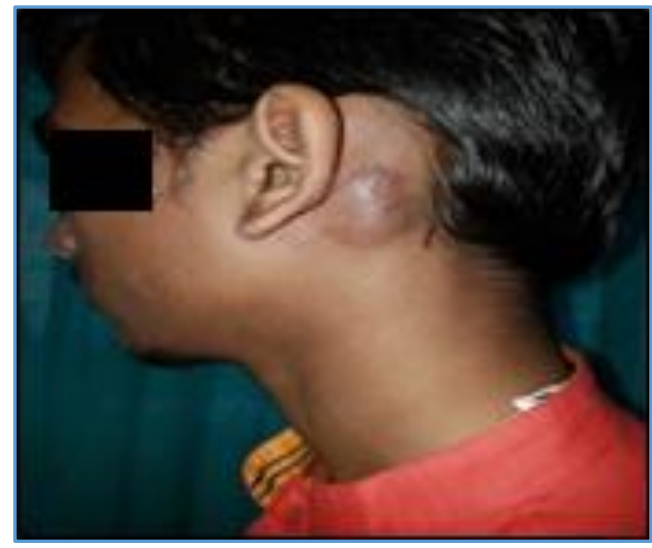

B. Left

ii) Intraoperative Pictures

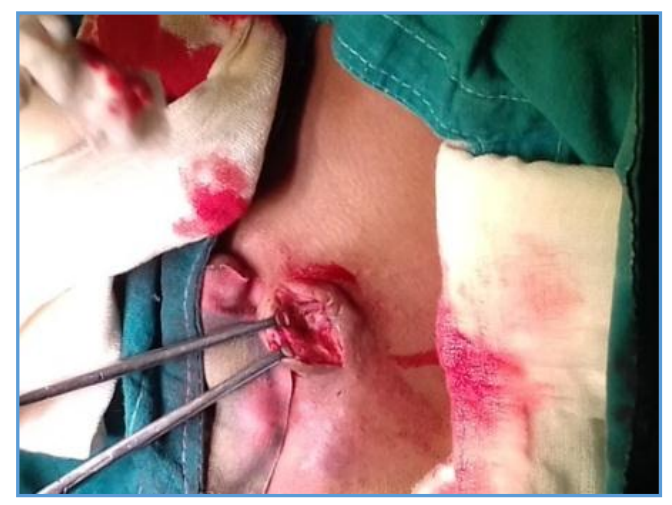




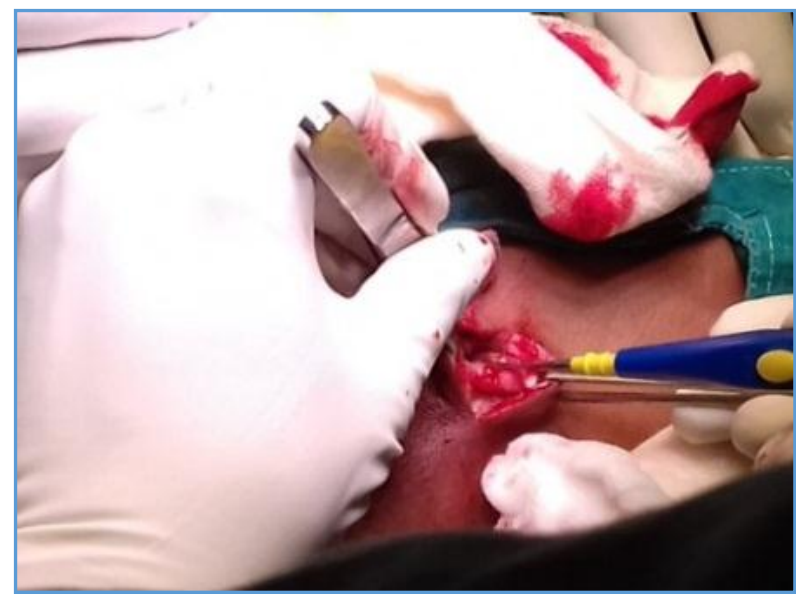

PATHOLOGICAL DISCUSSION

On evaluation, Haemoglobin levels $6.3 \mathrm{gm} / \mathrm{dL}$, Absolute Eosinophil count 650 cells/microlitre, Ultrasonogram Neck suggestive of cervical lymphadenopathy. Renal function test was within normal limits. Fine Needle Aspirate Cytology suggestive of reactive lymphadenitis. Because of concern that the mass might be some lymphoproliferative disorder or neoplasm, an excision biopsy was planned.

Subsequently, patient underwent excision biopsy of both the swellings under general anaesthesia and specimen sent for Histopathological examination. Patient recovery was uneventful and discharged. No fresh complaints and no recurrence and no lesions/ complications on follow-up after ten days and one month.

Skin biopsy: -Dermis shows mononuclear cells, lymphocytes, plasma cells and eosinophils around blood vessels.

Histopathological examination was suggestive of Kimura's disease. Loss of lymph node architecture showing hyperplastic germinal follicles with folliculolysis and extensive infiltration of eosinophils, plasma cells and few neutrophils in the sinuses, paracortical region and medulla. Hyalinised blood vessels were seen in the cortex and paracortex. Foci of eosinophilic aggregates was seen.

\section{iii) Pictures of Specimen Slide taken from Microscope}

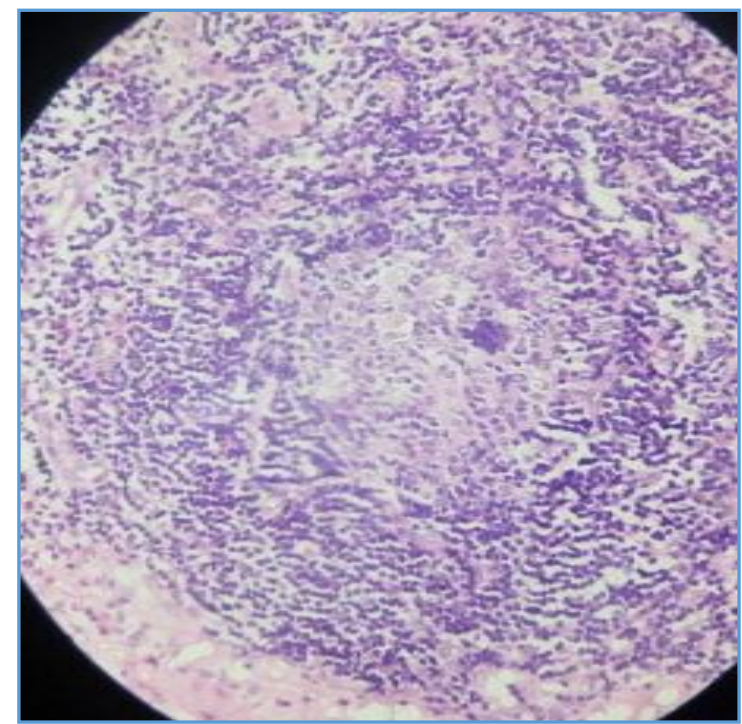

Hyperplasia of Germinal Centres

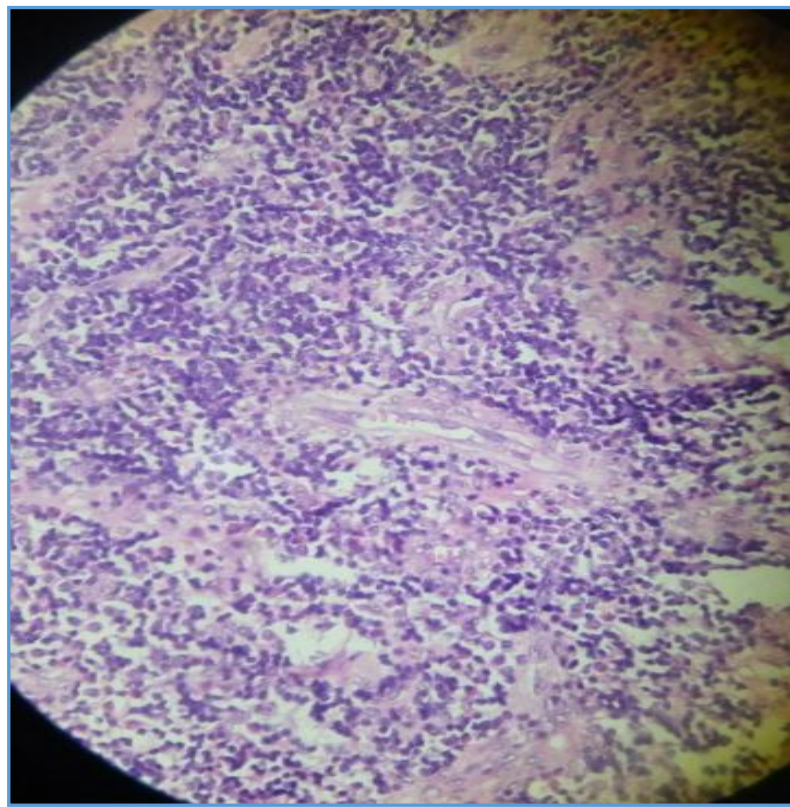

Hyalinised Vessels

iv) Post-Operative Pictures on Follow-Up

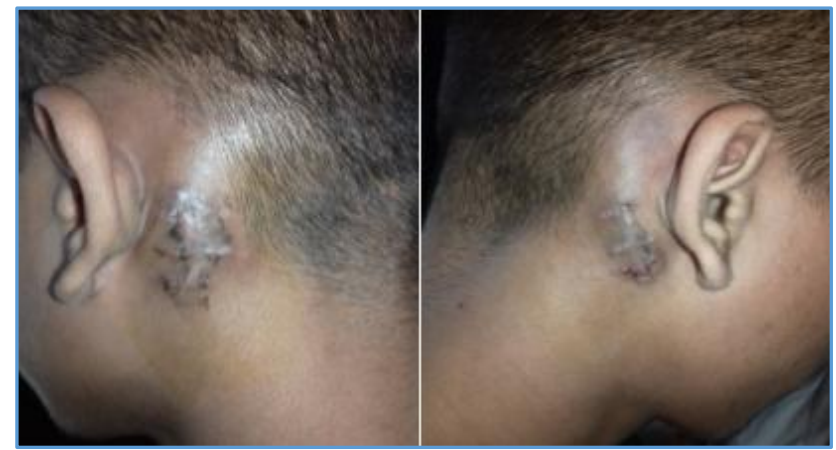

Kimura's disease was first reported by Kimm and Szeto in 1937 in China. In 1948, a Japanese doctor named Kimura et al published a description of the disease and formally coined it as 'Kimura's disease.'(1) The exact prevalence of KD is still undetermined,(2) but most of the cases typically occurs in young and middle-aged men originating from East Asia and South East Asia.(3)It affects young men between 20 and 40 years of age with a male: female ratio of 3:1.[14]

It is also known as eosinophilic lymphogranuloma and is a rare chronic inflammatory disorder with unknown aetiology and pathogenesis.(5),(6)However, the presence of eosinophilia and increased serum levels of IgE, mast cell, interleukin (IL)-4, IL-5 and IL-13 in patients suggests an aetiology of either an unusual autoimmune response or an immune reaction toward a parasitic infestation.(7)It usually presents as a painless subcutaneous softtissue swellings and associated with regional lymphadenopathy in the head and neck region (Other sites include groin, axilla, limbs).(8)Cases with systemic clinical signs have been described in the form of pruritus, eczema, rashes etc., but this is less common. ${ }^{[9]}$ Although, spontaneous resolution has been reported, most patients have a prolonged course with slow enlargement of the masses.[1] There is no potential that the lesions will become malignant. [1] 


\section{DISCUSSION OF MANAGEMENT}

Diagnosis of Kimura's disease is always a clinical dilemma with no specific diagnostic guideline. FNAC remains the initial investigation showing high numbers of eosinophils in background of lymphoid cells. Histopathological examination is required for definitive diagnosis, which iscommonly characterised by follicular hyperplasia with reactive germinal centers, microabscesses, fibrosis and proliferation of postcapillary venules.(8) The lesions can be further investigated with ultrasonography, CT scan and MRI. But their radiographic features are not pathognomonic. The diagnosis is made only by histopathological examination of excisional biopsy specimen of lesion.(10)

Treatment optionsinclude surgical resection, cytotoxic and radiation therapy as well as regional or systemic steroids therapy. In asymptomatic cases, conservativeobservation is often adequate as lesions occasionally undergo spontaneous resolution. The role of surgery is mainly for diagnostic and cosmetic purposes.(8)0ther treatment modalities are intralesional administration of steroids, cytotoxic agents and electrodesiccation. All-trans-retinoic acid with low dose prednisone induced remission in one case. Pranlukast a leukotriene receptor antagonist and cetirizine an $\mathrm{H} 1$ receptor blocker were also effective in inducing clinical remission in a few cases.[11]

Relapses are common and recurrence rate is as high as $40 \%$ despite early treatment.(12)Kimura's disease should be followed up closely, as it can produce thrombotic and renal complications.(1) Intriguingly, nephropathy is associated with $\mathrm{KD}$ in about $12 \%$ - $16 \%$ of patients, while the cause is unclear.(7)

As Kimura's disease is a rare entity, which is painless in nature with a chronic course. Given predominance of infectious aetiology in this region emphasis is to be made on identification, reporting and documenting similar cases in future, so as to increase our awareness of this disease and decide management.

Accordingly cases have to be evaluated and differentiated clinically and histologically from other conditions like lymphomas, Angiolymphoid Hyperplasia with Eosinophilia (ALHE) and other infectious aetiology. Aim of management in such cases is to preserve function and cosmetics of tissue affected. Although, prognosis can be good, complete cure is sometimes unattainable with chances of recurrence.

\section{ACKNOWLEDGEMENT}

We would like to acknowledge Dr. P Mallikarjun, our Unit Chief and Professor for his valuable insight and expertise in preparing this case report and Dr. Amatullah Farha, Pathology Resident for providing the relevant slide pictures.

\section{REFERENCES}

[1] Larroche C,Bletry O. Kimura's disease.Orphanet Encyclopedia2005: p. 1-3.

[2] Kar IB, Sethi AK. Kimura's disease: report of a case \& review of literature. J Maxillofac Oral Surg 2013;12(1):109-12.

[3] Wang DY, Mao JH, Zhang Y, et al. Kimura disease: a case report and review of the Chinese literature. Nephron ClinPract 2009;111(1):c55-c61.

[4] Pastapur R, Ansari A, Bohra RB, et al. Kimura disease a rare case. J Evol Med Dent Sci 2013;2:8860-3.

[5] Kimm H, Szeto C. Eosinophilic hyperplastic lymphogranuloma, comparison with Mikulicz's disease. Proc Chin Med Soc1937;1:329.

[6] Zhang JZ, Zhang CG, Chen JM. Thirty-five cases of Kimura's disease (eosinophilic lymphogranuloma). $\mathrm{Br}$ J Dermatol 1998;139(3):542-3.

[7] Sun QF, Xu DZ, Pan SH, et al. Kimura disease: review of the literature. Intern Med J 2008;38(8):668-72.

[8] Hashim HZ, Hoo FK, Lim SM, et al. Kimura disease - a case report and review of the literature. Pol Ann Med 2017;24:64-6.

[9] López-Arcas CJM, Iturriaga TM, Romero MP, et al. Kimura disease: report of a case in a Caucasian male and revision of the literature. Rev Esp Cir Oral Maxilofac2006;28:353-8.

[10] Das SK, Singh MK, Kundu I, et al. Kimura's disease: a rare cause of post-auricular swelling. Bengal Journal of Otolaryngology and Head Neck Surgery 2017;25(1):59-61.

[11] Kumar V, Salini, Haridas S. Kimura's disease: an uncommon cause of lymphadenopathy. Indian Journal of Medical and Paediatric Oncology: Official Journal of Indian Society of Medical \& Paediatric Oncology 2010;31(3):89-90.

[12] Goecmen H, Oguz H, Astarci M, et al. Kimura's disease: case report and brief review of the literature. J Otolaryngol 2006;35(5):358-60.

\section{FINAL DIAGNOSIS}

Kimura's Disease 